IJ§ER

ISSN: 2149-5939
International Journal of Social Sciences and Education Research

Online, http://dergipark.gov.tr/ijsser

Volume: 3(2), 2017

\title{
Çevresel Kuznets Eğrisi Hipotezinin Türkiye için geçerliliğinin sınanması: Granger Nedensellik Analizi
}

\author{
Validity Test of Environmental Kuznets Curve for Turkey: Granger Causality Analysis \\ Bedriye Tunçsiper ${ }^{1}$ Büşra Uçar²
}

Received Date: 01 / 09 / $2016 \quad$ Accepted Date: 20 / 02 / 2017

\begin{abstract}
$\ddot{O} z$
Çevreye Uyarlanmış Kuznets Ĕgrisi Hipotezine göre ekonomide yaşanan iktisadi büyüme ile birlikte çevre kirliliğinin belirli bir gelir seviyesine erişinceye kadar artacağ , bu gelir seviyesinden ulaşıldıktan sonra ise çevre kirliliğinin azalacă̆ını ileri sürmektedir. Bu çalışmada Çevreye Uyarlanmış Kuznets Ĕgrisi Hipotezinin Türkiye ekonomisi için geçerliliği araştırılmıştır. Analizde 1980-2011 dönemi yıllık verileri baz alınmıştır. $\mathrm{CO}_{2}$ emisyonu ve kişi başına düşen gelir değişkenleri arasındaki nedenselliğin varlı̆̆ının tespiti için Granger Nedensellik analizi yapılmıştır. Bu analizin sonucunda değişkenler arasında bir nedensellik bă̆ı tespit edilememiş olup Çevresel Kuznets Hipotezinin Türkiye için geçerli olmadı̆̆ sonucuna ulaşılmıştır.
\end{abstract}

Anahtar sözcükler: Çevresel Kuznets ĕgrisi, $\mathrm{CO}_{2}$ emisyonu, Granger nedensellik analizi

\begin{abstract}
Environmental Kuznets Curve Hypothesis asserts that environmental pollution and destruction increase with positive economic growth until a certain income level. When reached such a certain level, environmental pollution begins to decrease. In this study, the validity of Environmental Kuznets Curve Hypothesis is tested for Turkey. Annual data for 1980-2011 period is used for analysis. The relationship between CO2 emission and per capita income is analyzed with Granger Causality Test. According to the test result, it is found that Environmental Kuznets Curve is not valid for Turkish economy as the variables has no causal correlation between.
\end{abstract}

Keywords: Environmental Kuznets curve; $\mathrm{CO}_{2}$ emission; Granger causality analysis

\section{Giriş}

Son yıllarda ülkelerin genelinde meydana gelen çevresel tahribatların büyük boyutlara ulaşması, çevreyle ilişkili olan araştırmaların ve çalışmaların sayısının artması sonucunu doğurmuştur. Çevre pek çok faktörle etkileşim halindedir. Bu faktörlerden birisi de ekonomidir. Ekonomik büyümenin gerçekleşebilmesi için gerekli olan sanayileşme faaliyetleri hava kirliliği, küresel ısınma gibi çevresel tahribatlara neden olmakta bu da ekonomik kalkınma maliyetinin artmasına neden olmaktadır.

Üretimin gerçekleşebilmesi için gerekli olan doğal kaynakların ve hammaddenin büyük bir kısmı dış çevreden elde edilmektedir. Hammaddenin üretim sürecine dâhil edilmesiyle birlikte çevresel atıklar oluşmaya başlamakta, bu atıkların büyük bir kısmı geri dönüşüme dâhil edilmeden çevreye karışmakta ve sonuçta kaçınılmaz olarak çevre sorunları ortaya çıkmaktadır (Ulucak ve Erdem, 2012: 80).

\footnotetext{
${ }^{1}$ Balıkesir Üniversitesi, Balıkesir, Türkiye, tbedriye@, balikesir.edu.tr

${ }^{2}$ Balıkesir Üniversitesi, Balıkesir, Türkiye, busra.ucar.3190@hotmail.com
} 
Tunçsiper, B., Uçar, B. (2017). Çevresel Kuznets Eğrisi Hipotezinin Türkiye için geçerliliğinin sınanması: Granger nedensellik analizi. International Journal of Social Sciences and Education Research, 3(2), 657-666.

Çevresel Kuznets Eğrisi hipotezi, ekonomik büyüme ve çevresel kirlilik arasındaki ilişkiyi göstermeye çalışmaktadır. Bu çalışmada da ÇKE hipotezinin Türkiye ekonomisinin 1980- 2011 dönemindeki yıllık $\mathrm{CO}_{2}$ emisyonu ve kişi başına gelir verileri kullanılarak geçerliliği Granger Nedensellik Testi ile araştırılmıştır. Çalışmada Çevresel Kuznets Eğrisi hipotezinin teorik çerçevesi birinci bölümde incelenmiştir. İkinci bölümde ÇKE'nin literatür incelemesine yer verilmiştir. Üçüncü bölümde veri, yöntem açıklaması ve uygulaması yer almaktadır. Son olarak dördüncü bölümde ise ulaşılan ampirik bulgular değerlendirilerek yorumlanmıştır.

\section{2. Çevresel Kuznets Ĕgrisinin teorik çerçevesi}

Simon Kuznets (1955), yapmış olduğu çalışmada gelir dağılımı ve ekonomik büyümenin birbirleriyle ilişki içerisinde olduğu fikrini ileri sürmüştür. Çalışmasında, ekonomik büyüme gerçekleştiğinde kişi başına düşen gelirin ve büyümenin ilk safhasındaki gelir adaletsizliğinin artmakta olduğunu ancak kişi başına düşen gelirin belirli bir seviyeye ulaşmasından sonra gelir adaletsizliğinin azalmaya başladığını gözlemlemiştir. Kuznets, bu iki faktör arasındaki ilişkiyi ters U biçimindeki bir eğriyle açıklamıştır ve eğri literatürde Kuznets Eğrisi olarak geçmektedir. Bu hipotezden hareketle 1990' l1 yıllarda Grossman ve Krueger, çevresel konuların önem kazanması nedeniyle Kuznets hipotezini çevreye uyarlamış ve çalışmalarını "Çevresel Kuznets Eğrisi (ÇKE)" olarak isimlendirmişlerdir (Grossman ve Krueger, 1991).

ÇKE hipotezi çevresel tahribat ile kişi başına düşen gelir seviyesi arasındaki ilişkiyi açıklamaktadır. Bu hipoteze göre ekonomik büyüme sürecinde çevre tahribatı başlangıçta artmakta, büyümenin belirli bir seviyeye ulaşmasıyla birlikte çevre tahribatı azalmakta ve çevreyi korumaya yönelik olan politikaların önem kazanmasıyla çevresel iyileşmeler sağlanmaktadır.

Şekil 1.Çevreye Uyarlanmış Kuznets Eğrisi

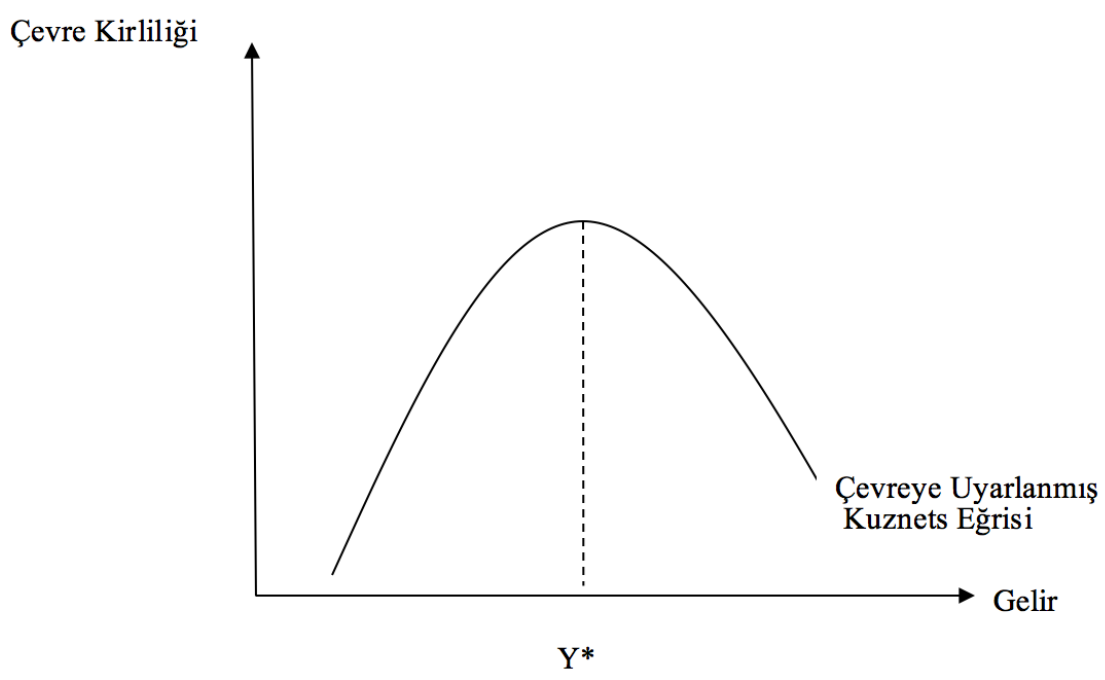

Şekil 1 Çevresel Kuznets Eğrisini göstermektedir. Kişi başına düşen gelir Y* seviyesine erişinceye kadar çevre kirliliği artmakta, $\mathrm{Y}^{*}$ seviyesinden itibaren ise azalan bir seyir göstermeye devam etmektedir. Sanayileşmenin ilk aşamasında kişiler çevre sorunlarından ziyade gelir elde etme, iş bulma gibi konulara öncelik vermektedirler. Gelir seviyesinin artmasıyla birlikte kişilerin çevreye olan duyarlılıkları artmakta, devletlerde çevresel politikalara daha fazla ağırlık vermeye başlamakta ve dolayısıyla çevre kirliliklerinde azalmalar görülmektedir. 
Tunçsiper, B., Uçar, B. (2017). Validity Test of Environmental Kuznets Curve for Turkey: Granger Causality Analysis. International Journal of Social Sciences and Education Research, 3(2), 657-666.

Kişi başına düşen gelir ile çevre kirliliği arasındaki ilişkiyi açıklayan ÇKE'nin ters U biçiminde olmasını belirleyen üç faktör vardır. Bu faktörler ölçek etkisi, yapısal etki ve teknolojik etkidir. Ölçek etkisi sanayileşmenin ilk aşamalarında görülmektedir. Üretim miktarı arttıkça üretimde kullanılan enerji ve kaynak miktarında bir artış yaşanacaktır, bu durum çevreye daha fazla atık bırakılmasına ve dolayısıyla çevresel kirliliğe neden olmaktadır. Ölçek etkisi, ÇKE'nin artan kısmıyla ilişkilendirilmektedir ve ölçek etkisinde ekonomik büyümenin çevreye olan etkisi negatif yöndedir. İkinci etki olan yapısal etki ise ekonomideki büyüme sürecinin devam etmesi halinde görülen yapısal dönüşümlerdir. Gelir seviyesi arttıkça ekonomi, sanayi sektöründen daha az doğal kaynak kullanımına ihtiyaç duyulan sektörler olan hizmet ve bilgi sektörüne geçiş yaşayacaktır. Yapısal etkide ekonomik büyüme çevreye pozitif yönde etki edecektir. Son olarak teknolojik etki ÇKE'nin azalan kısmına karşılık gelmektedir. Ülkelerin ekonomik büyümeyle birlikte refahının artması Ar-Ge çalışmalarının önem kazanmasına neden olacak ve çevresel kirliliğine neden olan teknolojiler yerine temiz, çevre dostu olan teknolojiler üretime koşulacaktır.

\section{Literatür incelemesi}

Literatür incelendiğinde Çevresel Kuznets Eğrisini konu alan birçok çalışma karşımıza çıkmaktadır. Bu çalışmalarda kullanılan değişkenlerin, ele alınan dönemin, kullanılan ekonometrik yöntemlerin ve analizi yapılan ülkelerin çeşitlilik göstermesi nedeniyle ulaşılan sonuçlar farklılık arz etmektedir. Türkiye için yapılan analizlerde ise kabul gören ortak bir sonuca ulaşılamamiştır.

İncelenen çalışmalarından bazıları şunlardır:

Grossman ve Krueger (1995), ÇKE’nin varlığını inceleyen ilk çalışma olarak karşımıza çıkmaktadır. Analizde 42 NAFTA ülkesinde ele alınmış olup, hava kirliliği ve ekonomik büyüme arasındaki ilişkiyi yatay kesit yöntemiyle incelemişlerdir. Sonuç olarak çevre ve gelir arasında ters U biçiminde bir ilişki olduğunu saptamış olup ÇKE hipotezini doğrulayan bir sonuç elde etmişlerdir.

Panayotou (1997), yapmış olduğu çalışmada 1982-1994 yılları arasındaki dönemi ele almış ve 30 ülke için analiz yapmıştır. Çalışmasında $\mathrm{SO}_{2}$ (kükürdioksit) emisyonunu dikkate almış ve nüfus yoğunluğunu da analizine dahil etmiştir. Netice itibariyle ÇKE'nin ters U biçiminde olduğunu yani ÇKE hipotezinin analize konu olan 30 ülke için geçerli olduğunu bulmuştur.

Atıcı ve Kurt (2007), Türkiye'nin 1968-2000 yılları arasındaki dönemi için $\mathrm{CO}_{2}$, dış ticaret ve gelir değişkenlerini kullanarak yaptıkları çalışmada ÇKE'yi doğrular sonuçlara ulaşmışlardır.

Başar ve Temurlenk (2007), çalışmalarında Türkiye'yi ele alarak 1950-2000 dönemi için $\mathrm{CO}_{2}$ ve gelir arasındaki ilişkiyi araştırmışlardır. $\mathrm{Bu}$ analizin sonucunda ÇKE hipotezinin Türkiye için geçerli olmadığı sonucuna varmışlardır.

Arı ve Zeren (2011), Akdeniz ülkelerini ele alarak $\mathrm{CO}_{2}$ ve kişi başına düşen gelir arasındaki ilişkiyi 2000-2005 dönemi için panel veri analiz yöntemini kullanarak analiz etmişlerdir. Analiz bulgularına göre $\mathrm{CO}_{2}$ ve kişi başı gelir arasındaki ilişkinin $\mathrm{N}$ biçimde olduğu yani yüksek büyüme düzeylerinde de $\mathrm{CO}_{2}$ emisyonunun artabileceği sonucuna ulaşılmış olup ÇKE hipotezinin Türkiye için geçerli olmadığı sonucunu saptamışlardır. 
Tunçsiper, B., Uçar, B. (2017). Çevresel Kuznets Eğrisi Hipotezinin Türkiye için geçerliliğinin sınanması: Granger nedensellik analizi. International Journal of Social Sciences and Education Research, 3(2), 657-666.

Güriş ve Tuna (2011), 88 ülkeyi analize dahil ederek 1971-2008 dönemi için ÇKE geçerliliğini parametrik panel veri modeliyle incelemişler ve ÇKE'nin bu ülkelerde geçerli olduğu sonucuna ulaşmışlardır.

Dumrul ve Saatçi (2012), Türkiye için yapmış oldukları analizde, çevre kirliliği ve ekonomik büyüme arasındaki ilişkiyi 1950-2007 dönemi için yapısal kırılmalı birim kök testi ve eş bütünleşme analizi ile test etmişlerdir. Elde edilen sonuçlara göre Türkiye'de ÇKE hipotezinin geçerli olduğu yani ÇKE’nin ters U biçimde olduğunu doğrulamışlardır.

Dam, Karakaya ve Bulut (2013), Türkiye için yapmış oldukları çalışmada ekonomik büyüme, enerji tüketimi ve sera gazı emisyonları arasındaki ilişkiyi 1960-2010 dönemi için dinamik en küçük kareler yöntemiyle araştırmışlar ve ÇKE'nin ters N biçiminde olduğu sonucuna ulaşmışlardır. Buldukları bu sonuç ÇKE hipotezini doğrulamamaktadır.

Öztürk ve Acaravcı (2013), Türkiye'nin 1960-2007 dönemi için yaptıkları çalışmada ticaret, finansal genişleme, ekonomik büyüme ve karbon emisyonları değişkenlerini kullanarak bu değişkenler arasındaki ilişkiyi test etmişler ve ÇKE hipotezinin Türkiye için geçerli olduğu sonucunu elde etmişlerdir.

Erataş ve Uysal (2014), BRICT ülkeleri için gelir düzeyi ve çevre kirliliği değiş̧kenleri arasındaki ilişkiyi panel veri yöntemiyle incelemişler ve sonuç olarak BRICT ülkelerinde ÇKE yaklaşımının geçerli olduğu sonucuna ulaşmışlardır.

Koçak (2014), yaptığı çalışmada Türkiye' de ÇKE hipotezinin geçerliliğini; $\mathrm{CO}_{2}$ emisyonu, gelir ve enerji tüketimi değişkenlerini kullanarak 1960-2010 yılları arasındaki dönem için ARDL sınır testi yaklaşımı ile test etmiştir. Bu test sonucuna göre Türkiye'de ilgili dönemde ÇKE hipotezini destekleyen sonuçlara ulaşılmamıştır.

Erdoğan, Türköz ve Görüş (2015), yaptıkları çalışmada ÇKE hipotezinin Türkiye için geçerliliğini sınamışlardır. 1975-2010 dönemini ele alarak $\mathrm{CO}_{2}$ ve gelir seviyesi arasındaki ilişkiyi ARDL sınır testi ve Toda-Yamamoto Granger nedensellik testleriyle araştırmışlardır. Ulaşılan ekonometrik sonuçlara göre ÇKE hipotezinin Türkiye için geçersiz olduğu saptanmıştır.

Lebe (2016), ÇKE hipotezinin geçerliliğini Türkiye'nin 1960-2010 dönemini ele alarak s1namıştır. Finansal gelişme, dışa açıklık, ekonomik büyüme ve $\mathrm{CO}_{2}$ emisyonu değişkenleri arasındaki ilişkiyi ARDL sınır testi ve Granger nedensellik testiyle analiz etmiş hipotezin Türkiye için geçerli olduğu sonucuna ulaşmıştır.

Topallı (2016), $\mathrm{CO}_{2}$ emisyonu ve ekonomik büyüme arasındaki ilişkiyi Çin, Hindistan, Brezilya ve Güney Afrika ülkelerinin 1980-2010 yılları arasındaki dönemi için panel nedensellik ve panel eşbütünleşme yöntemiyle araştırmıştır. Yapılan analizin sonucuna göre kısa ve uzun dönemde $\mathrm{CO}_{2}$ emisyonundan ekonomik büyümeye doğru tek yönlü nedensellik ilişkisi tespit edilmiştir.

\section{Türkiye için çevre kirliliği ve kişi başına düşen gelir ilişkisi üzerine bir uygulama}

\subsection{Veri Seti}

Çalı̧̧mada Türkiye ekonomisinde 1980-2011 dönemi için yıllık veriler kullanılarak $\mathrm{CO}_{2}$ emisyonu ve kişi başına düşen gelir arasındaki ilişki araştırılmıştır. 
Tunçsiper, B., Uçar, B. (2017). Validity Test of Environmental Kuznets Curve for Turkey: Granger Causality Analysis. International Journal of Social Sciences and Education Research, 3(2), 657-666.

$\mathrm{CO}_{2}$ Emisyonu $\left(\mathrm{CO}_{2}\right)$ : Fosil yakıtlar: petrol, doğal gaz, kömür vb. yanması sonucu karbondioksitin atmosfere karışması.

Kişi Başına Düşen Gelir (PPP): Satın alma gücü paritesine göre kişi başına düşen gelir seviyesi.

Analizde çevresel kirlilik göstergesi olarak $\mathrm{CO}_{2}$ alınmıştır. Bunun sebebi, $\mathrm{CO}_{2}{ }^{\prime}$ nin çevresel kirlilik üzerindeki etkisinin yüksek olmasındandır. Bağımlı değişken olan $\mathrm{CO}_{2}$ verileri Türksat Veri Analiz Portalından alınmıştır. Bağımsız değişken olan kişi başına düşen gelir seviyesi ise TÜİK' den derlenerek oluşturulmuştur. Çalışmada kullanılan $\mathrm{CO}_{2}$ emisyonu ve kişi başına gelir değişkenlerinin logaritması alınarak analize dahil edilmiştir.

\subsubsection{Birim Kök Testi}

Analizin ilk aşamasında $\mathrm{CO}_{2}$ emisyonu ve kişi başına gelir arasındaki uzun dönem ilişki incelenecektir. Değişkenler arasındaki nedensellik analizine geçmeden önce analize konu verilerin durağan olup olmadıklarını belirlemek ve sahte regresyon probleminden kaçınabilmek için Genişletilmiş Dickey Fuller (ADF) ve Phillips Perron (PP) birim kök sınamalarından yararlanılmış ve sonuçlar aşağıdaki Tablo 1'de sunulmuştur.

Tablo 1. ADF Testi Sonuçları

\begin{tabular}{|c|c|c|c|c|c|c|c|}
\hline \multicolumn{2}{|c|}{ Değişkenler } & T İstatis- & $\mathbf{0 1}$ & $\mathbf{\% 5}$ & $\mathbf{\% 1 0}$ & P Değeri \\
\hline \multirow{2}{*}{ LNCO $_{2}$} & Düizeyde & $\begin{array}{c}\text { Trendli } \\
\text { ve Sabit } \\
\text { Terim }\end{array}$ & -2.5859 & -4.2845 & -3.5628 & -3.2152 & 0.2886 \\
\cline { 2 - 8 } & $\mathbf{1 . F a r k}$ & $\begin{array}{c}\text { Sabit } \\
\text { Terim }\end{array}$ & -6.1260 & -3.6701 & -2.9639 & -2.6210 & $0.0000^{*}$ \\
\hline \multirow{2}{*}{ LnPPP } & Düzeyde & $\begin{array}{c}\text { Trendli } \\
\text { ve Sabit } \\
\text { Terim }\end{array}$ & -2.3073 & -4.2845 & -3.5628 & -3.2152 & 0.4179 \\
\cline { 2 - 8 } & $\mathbf{1 . f a r k}$ & $\begin{array}{c}\text { Sabit } \\
\text { Terim }\end{array}$ & -5.7879 & -3.6701 & -2.9639 & -2.6210 & $0.0000^{*}$ \\
\hline
\end{tabular}

Tablo 2. PP Testi Sonuçları

\begin{tabular}{|c|c|c|c|c|c|c|c|}
\hline \multicolumn{2}{|c|}{ Değişkenler } & & $\begin{array}{c}\text { T İstatis- } \\
\text { tiği }\end{array}$ & $\mathbf{\% 1}$ & $\mathbf{\% 5}$ & $\mathbf{\% 1 0}$ & P Değeri \\
\hline \multirow{2}{*}{ LNCO $_{2}$} & Düzeyde & $\begin{array}{c}\text { Trendli } \\
\text { ve Sabit } \\
\text { Terim }\end{array}$ & -2.5294 & -4.2845 & -3.5628 & -3.2152 & 0.3128 \\
\cline { 2 - 8 } & $\mathbf{1 . F a r k}$ & $\begin{array}{c}\text { Sabit } \\
\text { Terim }\end{array}$ & -6.1620 & -3.6701 & -2.9639 & -2.6210 & $0.0000^{*}$ \\
\hline \multirow{2}{*}{ LnPPP } & Düzeyde & $\begin{array}{c}\text { Trendli } \\
\text { ve Sabit } \\
\text { Terim }\end{array}$ & -2.3460 & -4.2845 & -3.5628 & -3.2152 & 0.3986 \\
\cline { 2 - 8 } & $\mathbf{1 . f a r k}$ & $\begin{array}{c}\text { Sabit } \\
\text { Terim }\end{array}$ & -5.7876 & -3.6701 & -2.9639 & -2.6210 & $0.0000^{*}$ \\
\hline
\end{tabular}

Seriler y1llık olduğu için gecikme uzunluğu Akaike bilgi kriterine göre gecikme uzunluğu 5 olarak alınmıştır. 1980-2011 dönemi için çalışmada kullanılan $\mathrm{CO}_{2}$ emisyonu ve kişi başına gelir değişkenlerinin düzeyde durağan olup olmadığı tespit edilmeye çalışılmıştır. 
Tunçsiper, B., Uçar, B. (2017). Çevresel Kuznets Eğrisi Hipotezinin Türkiye için geçerliliğinin sınanması: Granger nedensellik analizi. International Journal of Social Sciences and Education Research, 3(2), 657-666.

Tablo 1 ve tablo 2'de de görüldüğü gibi ADF ve PP birim kök testine göre $\mathrm{CO}_{2}$ emisyonu $\left(\mathrm{LNCO}_{2}\right)$ ve kişi başına gelir (LNPPP) serilerinin düzey değerleri için birim kökün bulunduğunu ifade eden $\mathrm{H}_{\mathrm{o}}$ hipotezi reddedilmemiş ve serilerin durağan olmadığına karar verilmiştir. $\mathrm{LNCO}_{2}$ ve LNPPP serilerinin 1. farkı alındığında t istatistik değeri \%1 kritik değerin üzerinde olduğu için $\mathrm{H}_{0}$ hipotezi reddedilmiş ve seriler durağan hale gelmiştir.

\subsubsection{Serilerin Arasindaki Nedenselliğin İncelenmesi}

Ele alınan değişkenlerin arasındaki ilişki ve bu ilişkinin yönü Granger Nedensellik Testi kullanılarak incelenmiştir. Ekonometrik modelimizde kullandığımız iki değişkende birinci farklarında durağan olduğundan Granger Nedenselli Testi yapılabilir.

Nedensellik denklemimiz şu şekilde tahmin edilmiştir:

$$
\begin{aligned}
& \Delta L N C O 2 t=\alpha 1 \sum_{i=1}^{m} \beta 1 i \Delta L N P P P t-i+\sum_{i=1}^{n} Y 1 \Delta L N C O 2 t-i+u t \\
& \Delta L N P P P t=\alpha 2 \sum_{i=1}^{m} \beta 2 \Delta L N C O 2 t-1+\sum_{i=1}^{n} Y 2 \Delta L N P P P t-i+u t
\end{aligned}
$$

$\mathrm{CO}_{2}$ emisyonu ve kişi başına gelir arasındaki nedensellik ilişkisi belirlenirken gecikme uzunluğu 1 olarak saptanmış ve Tablo 2' de Granger nedensellik analizi sonuçları gösterilmiştir.

Tablo 3. Granger (1969) Nedensellik Testi sonuçları

\begin{tabular}{|l|l|l|l|ll|}
\hline Nedensellik İlişkisi & Gecikme Sayısı & F İstatistiği & Olasılık değeri & Karar & \\
\hline $\mathrm{LNCO}_{2} \rightarrow \mathrm{LNPPP}$ & 1 & 1,00994 & 0,3792 & $\begin{array}{l}\text { Nedensellik } \\
\text { mamaktadır }\end{array}$ & Bulun- \\
\hline $\mathrm{LNPPP} \rightarrow \mathrm{LNCO}_{2}$ & 1 & 1.49688 & 0,2440 & $\begin{array}{l}\text { Nedensellik Bulun- } \\
\text { mamaktadır }\end{array}$ & \\
\hline
\end{tabular}

Uygun gecikme uzunluğunun 1 olduğu durumda Granger nedensellik testi sonuçları analiz edildiğinde Türkiye ekonomisinde $\mathrm{CO} 2$ emisyonundan kişi başına düşen gelir seviyesine doğru ve kişi başına düşen gelir seviyesinden $\mathrm{CO}_{2}$ emisyonuna doğru bir nedensellik ilişkisinin varlığı tespit edilememişsir.

\section{Sonuç ve değerlendirme}

Ekonomik büyüme olgusunun, ülkelerin her dönemde üzerinde önemle durdukları bir konu olduğu tartışmasızdır. 1990'dan itibaren ise çevresel kirliliğin ve sorunların artması nedeniyle dünya gündeminde çevresel konular yerini almış ve günümüzde de önemini korumaya devam etmektedir. Bu iki önemli konuyu temel alan Çevresel Kuznets Hipotezi, ülkelerin ekonomik büyümelerini gerçekleştirmesiyle birlikte çevresel sorunlarının da azalacağı temeline dayanmaktadir.

Bu araştırmada Çevresel Kuznets Hipotezinin geçerliliği Türkiye ekonomisi için 1980-2011 dönemine ait zaman serileriyle Granger nedensellik analizi kullanılarak ekonometrik olarak incelenmiştir. Yapılan Granger nedensellik analizi sonucunda Türkiye'de 1980-2011 döneminde $\mathrm{CO}_{2}$ emisyonu ve kişi başına düşen gelir seviyesi arasında herhangi bir nedensellik bağı bulu- 
Tunçsiper, B., Uçar, B. (2017). Validity Test of Environmental Kuznets Curve for Turkey: Granger Causality Analysis. International Journal of Social Sciences and Education Research, 3(2), 657-666.

namamış ve Çevresel Kuznets Hipotezinin Türkiye ekonomisinde geçerli olmadığı sonucuna varılmıştır.

Literatür incelemesinde de karşılaştığımız gibi ele alınan veriler, kullanılan analiz yöntemi ve zaman dilimi farklılaştıkça $\mathrm{CO}_{2}$ emisyonu ve kişi başına düşen gelir seviyesi arasındaki ilişkinin sonucu farklılaşmaktadır. Bu çalışmada yapılan ekonometrik analizin sonucu Dam, Karakaya ve Bulut (2013), Koçak (2014), Erdoğan, Türköz ve Görüş (2015), Başar ve Temurlenk (2007), Arı ve Zeren (2011) çalışmalarıyla paralellik göstermekte yani ÇKE hipotezinin Türkiye'de geçerli olmadığını doğrulamıştır. Ancak ÇKE hipotezini Türkiye için inceleyen diğer çalışmalardan olan Dumrul ve Saatçi (2012), Öztürk ve Acaravcı (2013), Lebe (2016) çalışmaları yaptığımız analizin sonucuyla uyumlu değildir.

Yapılan ampirik testler sonucu Çevresel Kuznets hipotezinin Türkiye'de geçersiz çıkmasının izahı şu şekilde yapılabilir. Türkiye'nin yüksek büyüme hızı yakalayamadığı ilk zamanlarında üretimini, $\mathrm{CO}_{2}$ salınımı yüksek olan fosil yakıtlar yerine yenilenebilir enerji kaynaklarını ve hidroelektrik santrallerinden elde ettiği elektrik enerjisini $\mathrm{CO}_{2}$ salınımı düşük olan enerji kaynaklarıyla üretimini gerçekleştirmiş olması nedeniyle gelir seviyesini arttırdığı ilk yıllarında $\mathrm{CO}_{2}$ emisyonu da azalma göstermiş̧ir. Ekonomik büyümenin belirli bir seviyeye erişmesi ve üretimin artmasıyla birlikte üretim sürecine dahil edilen fosil yakıt miktarının arttırılmasıyla $\mathrm{CO}_{2}$ salınımı miktarında da artış göstermiştir. Tüm bunlar ÇKE hipotezinin Türkiye' de geçersiz olma sebepleri arasında gösterilebilir.

Türkiye enerji ihtiyacının \% 89,3' ünü fosil yakıtlardan sağlamakta ve ihtiyacı olan enerjinin büyük bir kısmını da ithal etmektedir. Fosil yakıt kullanımının en az 2030 yılına kadar önemini koruyacağı ve karbon emisyonu miktarında artışlar gözleneceği beklenmektedir. Bu beklentiler çevre ve dışa bağımlılık açısından Türkiye için karamsar bir görüntü oluşturmaktadır. $\mathrm{Bu}$ nedenle politika yapıcıların bu karamsar tabloyu kaldırmaları için yeni ve istikrarlı enerji politikaları oluşturmaları, yenilenebilir enerji kaynaklarının kullanımını teşvik etmek amacıyla çeşitli vergi indirimleri ve sübvansiyonlarla desteklemeleri gerekmektedir. Tüm bunlar hem çevresel kalitenin arttırılması anlamında hem de dış açığın azalmasıyla birlikte ekonomik büyüme üzerinde olumlu sonuçlar doğuracaktır.

\section{Kaynakça}

Arı, A. ve Zeren, F. (2011). "CO2 Emisyonu ve Ekonomik Büyüme: Panel Veri Analizi”, Yönetim ve Ekonomi Dergisi, 18(2), ss.37-47.

Atıcı, C. ve Kurt, F. (2007). “ Türkiye'nin dış ticareti ve çevre kirliliği: Çevresel Kuznets eğrisi yaklaşımı”, Tarım Ekonomisi Dergisi, 13(2), ss.61-69.

Başar, S. ve Temurlenk, M. S. (2007). “Çevreye Uyarlanmış Kuznets Eğrisi: Türkiye Üzerine Bir Uygulama”, Iktisadi ve İdari Bilimler Dergisi, 21(1), ss.1-12.

Dam, M., Karakaya, E. ve Bulut, Ş. (2013). "Çevresel Kuznets Eğrisi ve Türkiye: Ampirik Bir Analiz”, Dumlupınar Üniversitesi Sosyal Bilimler Dergisi”, EYİ 2013 Özel Sayı1

Erataş, F. ve Uysal, D. (2014). "Çevresel Kuznets Eğrisi Yaklaşımının "BRICT" Ülkeleri Kapsamında Değerlendirilmesi”, Iktisat Fakültesi Mecmuası, 64(1), ss.1-25.

Erdoğan, İ., Türköz, K. ve Görüş, M. Ş. (2015). “Çevresel Kuznets Eğrisi Hipotezinin Türkiye Ekonomisi İçin Geçerliliğ̈i”, Dumlupınar Üniversitesi Sosyal Bilimler Dergisi, 44. 
Tunçsiper, B., Uçar, B. (2017). Çevresel Kuznets Eğrisi Hipotezinin Türkiye için geçerliliğinin sınanması: Granger nedensellik analizi. International Journal of Social Sciences and Education Research, 3(2), 657-666.

Grossman, G. M. ve Krueger, A. B. (1991). "Environmental Impacts Of A North American Free Trade Agreement”, National Bureau Of Economic Research, 3914, pp.1-57.

Grossman, G. M. ve Krueger, A. B. (1995). "Economic Growth And The Environment", The Quarterly Journal Of Economics, 110(2), pp.353-357.

Güriş, S. ve Tuna, E. (2011). “Çevresel Kuznets Eğrisi'nin Geçerliliğinin Panel Veri Modelleriyle Analizi”, Trakya Sosyal Bilimler Dergisi, 13(2). ss.173-190.

Koçak, E. (2014). “Türkiye'de Çevresel Kuznets Eğrisi Hipotezinin Geçerliliği: ARDL Sınır Testi Yaklaşımı", İşletme ve İktisat Çalışmaları Dergisi, 2(3), ss.62-73.

Lebe, F. (2016). “Çevresel Kuznets Eğrisi Hipotezi: Türkiye İçin Eşbütünleşme ve Nedensellik Analizi”, Doğuş Üniversitesi Dergisi, 17 (2) 2016, ss.177-194.

Öztürk, I. ve Acaravci, A. (2013). "CO2 Emissions, Energy Consumption and Economic Growth in Turkey”, Renewable and Sustainable Energy Reviews, 14(9), pp.3220-3225.

Panayotou, T. (1997). "Empirical Tests And Policy Analysis Of Environmental Degradation At Different Stages Of Economic Development”, International Labour Organization, No:292778.

Saatçi, M. ve Dumrul, Y. (2012). “Çevre Kirliliği Ve Ekonomik Büyüme İlişkisi: Çevresel Kuznets Eğrisinin Türk Ekonomisi İçin Yapısal Kırılmalı Eş-Bütünleşme Yöntemiyle Tahmini”, Erciyes Üniversitesi Íktisadi ve İdari Bilimler Fakültesi Dergisi, 37, ss.65-86.

Topallı, N. (2016). “CO2 Emisyonu ve Ekonomik Büyüme Arasındaki İlişki: Hindistan, Çin, Brezilya ve Güney Afrika için Panel Veri Analizi”, Çankırı Karatekin Üniversitesi İ̈BF Dergisi, $<$ http://dx.doi.org/10.18074/cnuiibf.275>. (Çevrimiçi Erişim: 20.09.2016).

Turkstat Veri Analiz Portal1. (2016). <http://turkstat.org/>. (Çevrimiçi Erişim: 20.09.2016).

Türkiye İstatistik Kurumu. (2016). <http://www.tuik.gov.tr/>. (Çevrimiçi Erişim: 20.09.2016).

Ulucak, R. ve Erdem E. (2012). "Çevre-İktisat İlişkisi Ve Türkiye'de Çevre Politikalarının Etkinliği”, Akademik Araştırmalar ve Çalışmalar Dergisi, 4(6), ss.78-98. 
Tunçsiper, B., Uçar, B. (2017). Validity Test of Environmental Kuznets Curve for Turkey: Granger Causality Analysis. International Journal of Social Sciences and Education Research, 3(2), 657-666.

\section{Extended abstract in English}

Along with the increase in industrialization activities, harmonization with this process has resulted in a significant increase in the pollution of the environment that has emerged in the appropriate countries, the increase in the interest in showing the environment related issues, and the increase in the number of researches and studies related to the environment. The environment is in interaction with many factors. One of these factors is the economy. The industrialization activities required for countries to achieve economic growth cause environmental damages such as air pollution and global warming, leading to an increase in the cost of economic development.

A large part of the raw material, which is part of the production process, is obtained from the outside. With the inclusion of the raw material into the production process, environmental wastes are beginning to form and a large part of these wastes are mixed up without involvement of recycling, resulting in inevitably environmental problems.

Simon Kuznets (1955) argued that income distribution and economic growth are in relation to each other. In his work he observed that income per capita and economic growth in the first phase of growth were increasing but income inequality began to decline after per capita income reached a certain level. Kuznets explained the relationship between these two factors by a curve in the form of an inverted U-curve and the curve is referred to as the kuznets curve in the literature. Moving on from this hypothesis, Grossman and Krueger in the 1990s adopted the Kuznets hypothesis as an environmental criterion because of the importance of environmental issues and called their work "Environmental Kuznets Curve".

There are three factors that determine the opposite of the environmental kuznets curve, which describes the relationship between per capita income and environmental pollution. These factors are scale effect, structural effect and technological effect. The scale effect is seen in the first stages of the industrialization. As the amount of production increases, there will be an increase in the amount of energy and resources used in production, which causes more waste to leave the environment and thus environmental pollution. The scale effect is related to the increasing portion of the environmental Kuznets curve, and the environmental effect of economic growth on the scale effect is negative. The structural effect, which is the second effect, is the structural transformations seen as the continuation of the economic growth process.. As the income level increases, the economy will migrate to the services and information sector, which are sectors that need less natural resource use than the industry sector. Economic growth will have a positive effect on the environment in structural impact. Finally, the technological impact corresponds to the declining portion of the environmental Kuznets curve. Increasing economic growth and prosperity of the countries will cause research and development studies to gain importance and to produce clean, environmentally friendly technologies instead of technologies that cause environmental pollution.

In this study, the validity of the environmental kuznets hypothesis in Turkey was investigated by determining the causality relationship between the variables of $\mathrm{CO} 2$ emissions and per capita income level. In this context, annual $\mathrm{CO}_{2}$ emissions for the period 1980-2011 and income level per capita were used. First, the stability of the variables used in the study was tested with the aid of unit root tests. It can be seen that in the two variables considered, the level values are not static but become stable when the first differences are received. Then granger causality analysis 
Tunçsiper, B., Uçar, B. (2017). Çevresel Kuznets Eğrisi Hipotezinin Türkiye için geçerliliğinin sınanması: Granger nedensellik analizi. International Journal of Social Sciences and Education Research, 3(2), 657-666.

was used to determine the causality relationship between $\mathrm{CO}_{2}$ emissions and per capita income level variables.

According to the Granger causality analysis, no causal link between $\mathrm{CO}_{2}$ emissions in Turkey and the income level per capita has been found and the Environmental Kuznets Hypothesis is not valid in the Turkish economy.

As the data analyzed, the method of analysis used, and the time period differed as we did in the literature review, the result of the relationship between $\mathrm{CO}_{2}$ emissions and income per capita differs. The econometric analysis carried out in this study is in parallel with the results of the end result Dam, Karakaya and Bulut (2013), Koçak (2014), Erdoğan, Türköz and Görüş (2015), Başar and Temurlenk (2007) and Arı and Zeren Confirm that it is not valid in Turkey.However, Dumrul and Saatci (2012), Ozturk and Acaravc1 (2013) and Lebe (2016) are not compatible with the results of our analysis, which is one of the other studies that studies the circumstantial kuznets curriculum hypothesis for Turkey. The empirical tests that have been carried out can explain the outcome of the nullification of the Environmental Kuznets hypothesis in Turkey. In the early years when Turkey was unable to catch up with its high growth rate, its $\mathrm{CO}_{2}$ emissions decreased in the first years of its production, as it increased its level of income because it produced electricity from renewable energy sources instead of fossil fuels with high $\mathrm{CO}_{2}$ emissions and electricity from hydroelectric power plants with low $\mathrm{CO}_{2}$ emissions. As the economic growth reached a certain level and production increased, the amount of $\mathrm{CO}_{2}$ emissions increased as the amount of fossil fuel included in the production process was increased. All of these can be shown as the reasons for the environmental Kuznets hypothesis being invalid in Turkey.

Turkey supplies $89.3 \%$ of its energy needs from fossil fuels and imports most of the energy that the country needs to use in production. It is estimated that the use of fossil fuels will remain important until at least 2030 and increases in carbon emissions will be observed. These expectations create a pessimistic picture for Turkey in terms of environmental and external dependency. For this reason, policy makers need to create new and stable energy policies to remove this pessimistic picture and to support them with various tax breaks and subsidies to encourage the use of renewable energy sources. All this will have positive consequences for economic growth, both in terms of increasing environmental quality and in reducing external deficits. 